\title{
A dose-finding, long-term study on the use of calcium chloride in saline solution as a method of nonsurgical sterilization in dogs: evaluation of the most effective concentration with the lowest risk
}

\author{
Raffaella Leoci ${ }^{1 *}$, Giulio Aiudi ${ }^{1}$, Fabio Silvestre ${ }^{1}$, Elaine A Lissner ${ }^{2}$, Fabio Marino ${ }^{3}$ and Giovanni M Lacalandra ${ }^{1}$
}

\begin{abstract}
Background: Canine overpopulation is a global issue with serious health and welfare implications. Nonsurgical methods of sterilization could yield positive impacts on this problem, but no long-term data on such methods are available. The objective of the current investigation was to determine the effects of intratesticular injections of calcium chloride dihydrate $\left(\mathrm{CaCl}_{2}\right)$ in saline in dogs over a one year period. Five concentrations $(0 \%, 10 \%, 20 \%, 30 \%$, $60 \%)$ of $\mathrm{CaCl}_{2}$ in saline were administered via intratesticular injection to groups of 10 dogs each. Total sperm count and motility, blood levels of testosterone, and side effects were examined at 0, 2, 6, and 12 months post-injection (PI). Testicular size and semen volume were examined at 0 and 12 months PI.
\end{abstract}

Results: Total sperm count, semen volume and testosterone showed significant dose-dependent decreases upon treatment with $10 \%-60 \% \mathrm{CaCl}_{2}$ compared with either the control group $\left(0 \% \mathrm{CaCl}_{2}\right)$ or baseline for each treatment group. Azoospermia was achieved for at least 12 months PI in 60\% and $80 \%$ of treated dogs after administration of a $10 \%$ and $20 \% \mathrm{CaCl}_{2}$, respectively. Treatment with $30 \%$ or $60 \% \mathrm{CaCl}_{2}$ resulted in azoospermia in $100 \%$ of dogs, but more side effects were observed, while no side effects were noticed at lower doses. For each treatment group, testosterone levels had decreased an average of 35\%-70\% at 6 months following treatment. However, testosterone levels rebounded by the 12-month time point in all groups except the highest dosage group $\left(60 \% \mathrm{CaCl}_{2}\right)$, which remained at the low end of physiological range throughout the study. Sperm motility dropped to zero or near zero in all dogs treated with $\mathrm{CaCl}_{2}$. Testicular size was significantly smaller at 12 months $\mathrm{PI}$ for all groups when compared to baseline.

Conclusions: This first long-term study confirms reports of the efficacy of $\mathrm{CaCl}_{2}$ sterilization. However, at dosages free of adverse events, calcium chloride in saline may not provide permanent sterilization as previously believed. Future work should explore optimized solvents to increase the permanence of the well-tolerated 20\% formulation.

Keywords: Calcium chloride, Canine, Dog, Nonsurgical sterilization, Testicular injection, Population management

\footnotetext{
* Correspondence: leocivet@yahoo.it

'Department of Emergency and Organ Transplantation (DETO), Section of Veterinary Clinic and Animal Production, University of Bari Aldo Moro, SP per Casamassima km 3, 70010 Valenzano BA, Italy

Full list of author information is available at the end of the article
} 


\section{Background}

Canine overpopulation is an intractable problem globally despite local efforts to control population growth. In many developing countries, free-roaming dogs cause serious health and welfare problems with resulting socio-economic, ecological, political, and ethical issues. Therefore, the development of effective fertility control measures is a high priority. Many communities that aspire to mass surgical sterilization find it prohibitively resource-intensive. As a result, lifelong housing in shelters or mass euthanasia campaigns continue to be used to control dog populations, but the effects prove to be minor, not cost-effective, and often against international animal welfare regulations $[1,2]$. Thus, several alternatives to surgical sterilization have been explored. For contraception of stray male dogs, desirable methods need to be permanently effective, minimally invasive, simple, rapid, and inexpensive, with potential for adoption in large-scale animal birth control programs [3].

Intratesticular injection of chemicals is a non-surgical method for contraception of male dogs [4]. This approach has been investigated for more than five decades [5]. An ideal chemical sterilizing agent for stray dogs would be one that effectively arrests spermatogenesis, androgenesis, and libido, while lacking toxicity and serious side effects [6]. Many compounds have been studied (e.g., glycerol, zinc compounds, and chlorhexidine) [6-10]. While many potential candidates possess some anti-spermatogenic or anti-fertilizing activity, most compounds do not eliminate gonadal sources of testosterone [4]. In contrast, calcium chloride dihydrate $\left(\mathrm{CaCl}_{2}\right)$, a salt used for several medical purposes [11], represents a promising chemical sterilant $[12,13] . \mathrm{CaCl}_{2}$ can be dissolved in water $[12,13]$, in alcohol $[12,13]$, or lidocaine solution $[2,14,15]$. Several investigators $[2,14]$ have reported that a single, bilateral, intratesticular injection of $\mathrm{CaCl}_{2}$ solution resulted in induction of permanent (i.e., irreversible) chemosterilization, including cessation of sperm production and decreased testosterone in male dogs. These earlier studies evaluated the effectiveness of $\mathrm{CaCl}_{2}$ on testicular histology within two months of injection, and the concentration of sterilant used per testicle was frequently correlated with the animal body weight [2,12-14]. However, use of a concentration per body weight approach is not practical for application in the field, as stray or wild animals would have to be weighed and customized concentrations of sterilant prepared according to the weight of individual dogs. In order to determine an effective, permanent nonsurgical sterilization method for dogs, long-term data are needed evaluating and comparing the reproductive parameters and safety of various concentrations and formulations.

In the current study, the effects of a range of concentrations of $\mathrm{CaCl}_{2}$ on reproductive physiology and canine health were measured in male dogs over a 12-month period. The dosage of $\mathrm{CaCl}_{2}$ per testicle was based on testicular width. The goal was to compare the impact of different $\mathrm{CaCl}_{2}$ concentrations in physiological saline on sperm production, blood levels of testosterone, testicular size, adverse events, and long-term fertility.

\section{Methods \\ Animals}

Fifty mature, healthy, mixed-breed, owned male dogs 2 to 5 years of age (mean $=3.6$ years, $\mathrm{SD}=1.1$ years), weighing 18 to $24 \mathrm{~kg}$ (mean $=21.1 \mathrm{~kg}, \mathrm{SD}=2.2 \mathrm{~kg}$ ) were used. This study was conducted at a private shelter with cooperation of the shelter owner. Dogs remained at the shelter throughout the study. Good health status was confirmed by routine blood tests and clinical examinations. To assess the fertility of the dogs, an andrological examination including physical and ultrasonographic examinations and evaluation of semen quality was performed before the start of the study. All dogs showed sexual interest in a bitch in estrus.

Dogs received routine deworming and vaccinations. The dogs were not subjected to changes in habits during the study, were fed standard commercial dog food twice daily, and were given water ad libitum. Dogs were housed in groups of three in a comfortable primary enclosure with outdoor runs. Indoor space had temperature maintained above $15^{\circ} \mathrm{C}$ and below $26^{\circ} \mathrm{C}$ and relative humidity ranging from $30 \%$ to $70 \%$.

Investigations were conducted in accordance with the Principles for the Care and Use of Research Animals promulgated by the European Union. The Italian Ministry of Health (Progetto di Ricerca corrente 2009 IZS SI 11/09: "Randagismo applicazione e valutazione di metodi innovativi per il controllo delle nascite") approved this study.

\section{Experimental protocol}

Dogs were randomly divided into five groups (A-E) of 10 dogs per group. At day $0\left(\mathrm{~T}_{0}\right)$, semen evaluation and blood testosterone analysis were performed. Appropriate concentrations of $\mathrm{CaCl}_{2}$ sterilant were prepared as described below. After light sedation with an intramuscular (IM) injection of 5-10 mg of acepromazine maleate (Prequillan, Fatro, Italy) per $10 \mathrm{~kg}$, testicular width was measured with a caliper. Based on the scrotal width, the dosage of the experimental or control solution was injected in each testicle. Groups of dogs received 10\% (group A), 20\% (group B), 30\% (group C), or 60\% (group D) of $\mathrm{CaCl}_{2}$ or only saline solution (control group E). At 2, 6 and 12 months $\left(\mathrm{T}_{2}, \mathrm{~T}_{6}, \mathrm{~T}_{12}\right.$ respectively) post-injection (PI), semen was evaluated for total sperm count and progressive motility and blood testosterone concentrations were determined. Semen was evaluated for volume and testicles for width at $\mathrm{T}_{0}$ and $\mathrm{T}_{12}$. Throughout the trial, the dogs were under regular clinical observation. 
Preparation and intratesticular injection of $\mathrm{CaCl}_{2}$ solution Four solutions of $\mathrm{CaCl}_{2}$ were prepared. For each experimental group, $10 \mathrm{~g}$ (Group A), $20 \mathrm{~g}$ (Group B), $30 \mathrm{~g}$ (Group C), or $60 \mathrm{~g}$ (Group D) of $\mathrm{CaCl}_{2}$ powder (Sigma Aldrich Corporation) was dissolved in a physiological saline solution (Sodio Cloruro Bieffe Medital 0.9\%, Grosotto [SO], Italy) to a final volume of $100 \mathrm{ml}$, mixed, and sterilized in Falcon tubes. Sterile physiological saline served as the control solution. Prior to injection, fur from long-haired dogs was trimmed from the scrotum after the dogs were sedated. The scrotal skin was then gently washed with saline solution and disinfected with a sodium hypochlorite solution (0.05\% Amukine, Angelini, Italy).

Animals received single, bilateral intratesticular injections at a dose corresponding to the testicular width, according to a prior research protocol (personal communication, Dr. Kuladip Jana). Animals with scrotal diameters of 19-22 mm received $0.8 \mathrm{ml}$ injections, whereas animals with scrotal diameters of at least $23 \mathrm{~mm}$ wide received $1 \mathrm{ml}$ injections. The 10 animals in the control group $\mathrm{E}$, which all had testicular widths of at least $23 \mathrm{~mm}$, received single, bilateral intratesticular injections of $1 \mathrm{ml}$ of sterile saline solution.

To inject the solution, a 22 gauge/30 $\mathrm{mm}$ needle was inserted from the caudal pole of each testis approximately $5 \mathrm{~mm}$ from the epididymal tail, and directed towards the opposite pole of the testis. The solution was carefully deposited along the entire route from the proximal to the distal end by linear infiltration [16]. The injection was completed at a moderately slow pace (5-12 sec depending on volume) and all the solution was injected before the needle was withdrawn from the testis to prevent seepage of the solution from the injection site. When the injection was $1 / 3$ complete, the pressure applied to the testicle was reduced to accommodate the volume of fluid being injected. After the injection the needle was removed quickly while simultaneously releasing the testicle. No further intratesticular injections were performed on any of the animals throughout the rest of the study.

\section{Total sperm count volume and motility}

Semen was collected by digital manipulation of the penis [17] using plastic cones (artificial vaginas) (IMV Technologies, Italia). Semen was immediately collected in three fractions using sterile graduated tubes. To evaluate the effect of the chemical sterilization on semen characteristics, semen volume was recorded and analyzed. The second sperm-rich fraction of the ejaculate was examined within 30-60 min by computer-assisted sperm analysis (CASA) (IVOS Version 12.2; Hamilton Thorne Biosciences Inc., Beverly, MA, USA). This interval had been validated in preliminary studies not to significantly influence semen parameters (data not shown). During this period, the semen was stored at $37^{\circ} \mathrm{C}$. A $4 \mu$ l aliquot was mounted on a 4-chamber Leja ${ }^{\oplus}$ slide (Microptic S.L.) at $37^{\circ} \mathrm{C}$ and evaluated for sperm concentration and percentage of progressive motile sperm $[18,19]$. Total sperm count was then obtained.

\section{Assay for serum testosterone}

Between 8:00 a.m. and 8:30 a.m. at $\mathrm{T}_{0}$ to $\mathrm{T}_{12}$ dogs received subcutaneous injections of 1,000 international units of human chorionic gonadotrophin (hCG) (Creative Biomart, CD Inc.) in order to stimulate gonadal testosterone levels [20-22]. Blood was collected from the saphenous vein of each dog $120 \mathrm{~min}$ after the hCG injections. A portion of blood was allowed to stand for $10-15 \mathrm{~min}$ at $4^{\circ} \mathrm{C}$, then centrifuged at $1,500 \mathrm{~g}$ for $10 \mathrm{~min}$ at $4^{\circ} \mathrm{C}$ prior to aspiration of serum. Serum samples were stored at $-20^{\circ} \mathrm{C}$ until thawed and assayed for testosterone concentrations by a chemiluminescence technique (Immulite Immunoassay System, Siemens).

\section{Clinical examination}

All animals were subjected to routine clinical examination during the $T_{0}$ to $T_{12}$ period. After the chemical sterilization procedure, the animals were observed continuously for the first 72 hours, followed by daily observation for up to 15 days, with clinical examination again at 2, 6, and 12 months. Clinical examination included recording body weight, blood counts, general attitude, appetite, rectal temperature, scrotal and inguinal integument, palpation of testes, and heart and respiratory rates.

\section{Measurement of testicular width}

Testicular width of each testicle was measured as an index of testicular size [23]. Caliper measurements were obtained on each testicle at $\mathrm{T}_{0}$ and at $\mathrm{T}_{12}$.

\section{Adverse effects management}

In case of severe testicular side effects, dogs were surgically castrated. The surgically excised testes were sampled for histological examination. The testicles were fixed in Bouin's fixative and routinely processed for paraffin embedding by a previous de-scaling treatment (CAL-EX Decalcifier, Fisher Chemical, USA), followed by cutting on a microtome. Five-micron sections were stained with hematoxylin-eosin and von Kossa stain.

Representative microscopic fields were selected and digitized using software for image analysis. Morphometric measures were performed on scanned images to identify and quantify the extent of the lesions, by estimating changes in ratios of different cell types (including germ cells and stroma) and between intracellular components (nucleus/cytoplasm, volume, and morphology). 


\section{Statistical analysis}

Clinical data, treatment and time were included in the statistical analyses and average and standard deviation (SD) (mean \pm SD) calculated when appropriate. Statistical analyses were conducted using Statistica (StatSoft, Inc. Tulsa, OK, USA).

Repeated measures analysis of variance (ANOVA), with Time as the within factor and Group as the between factor, were used to evaluate three measurements in the five groups (A-E) across the four timepoints $\left(\mathrm{T}_{0}\right.$, $\mathrm{T}_{2}, \mathrm{~T}_{6}, \mathrm{~T}_{12}$ ) for semen characteristics and testosterone or two timepoints $\left(T_{0}, T_{12}\right)$ for semen volume and testicular width. If the overall test had statistical significance, then planned comparisons were conducted. Dunnett's test for comparison to control group E was used, as well as univariate or multivariate planned comparisons to determine if the measures changed after treatment and if the treated groups differed from the control group E. A two-tailed significance level of $P<0.05$ was identified.

Eight dogs underwent surgical castration and as a result had missing data for testosterone levels, semen volume, sperm motility, and testicular measurements (see Results).

\section{Results}

\section{Clinical observation}

All animals in the study tolerated the insertion of the needle and intratesticular injection well. Only a small number of dogs showed signs of slight discomfort during the $\mathrm{CaCl}_{2}$ or saline injection: $2 \%(1 / 50)$ of injected dogs vocalized, and $4 \%(2 / 50)$ had abdominal muscle contraction at needle puncture of the scrotum. Even though injection was performed carefully, seepage occurred in $2 \%$ of the dogs $(1 / 50)$, and the seepage was wiped away immediately with dry gauze. No adverse effects were noticed during the 12 months study in the dog where seepage occurred.

During the first two weeks after the $\mathrm{CaCl}_{2}$ injection, dogs in groups A and B did not exhibit any agitation, fever, or marked inflammatory swelling of the testis. However, all dogs (experimental and control groups) had a slight increase in the firmness of the testes on palpation from 24 hours PI and until PI days 3-7. Atrophy of the testes gradually progressed in groups A and B dogs from 1 week to approximately 1.5 months PI leaving a small fibrotic remnant.

In groups $C$ and $D$, some dogs showed sign of discomfort and licked the site of injection. Within two weeks, 2 dogs (20\%) in group $C$ and 6 dogs (60\%) in group $\mathrm{D}$ developed a testicular fistula. These 8 dogs underwent therapy with anti-inflammatory drugs and antibiotics and surgical castration. These dogs were excluded from the study.
No variation in body weight was recorded in any of the groups. Significant variation in the blood parameters was not found except for dogs excluded from the study. Dogs developing testicular fistula had leukocytosis indicating an inflammatory reaction (i.e., 21,000 white blood cells/ml[mean]).

\section{Adverse reactions}

Two dogs of group C and six of group D showed an inflamed scrotum by $72 \mathrm{~h}$ PI which developed into a scrotal ulcer and fistula in the following days. Surgical castration and scrotal ablation was conducted on day 15 PI. Histological examination of testicular tissue from orchiectomized dogs in group $\mathrm{C}$ showed massive necrosis surrounded by fibrous connective tissue and peripheral calcification (Figure 1). Sparse calcium deposits were present at the periphery of the testicles while the remaining tissue showed severe tubular degeneration. At higher magnification, the seminiferous epithelium was constituted of one or two cell layers lining the tubular lumen. Moreover, plasma cells, macrophage infiltration and the presence of numerous multinucleated giant and epithelioid cells were found inside the seminiferous tubules (Figure 2).

Histological examination of testicular tissue from orchiectomized dogs in group D showed large necrotic areas often surrounded by a thick granulomatous/fibrous reaction. The remaining parenchyma was constituted of seminiferous tubules severely degenerated and surrounded by diffuse interstitial fibrosis. Abundant interstitial calcium deposits, hemorrhages and rare giant cells, often inside the tubular lumen, were also present (Figure 3).

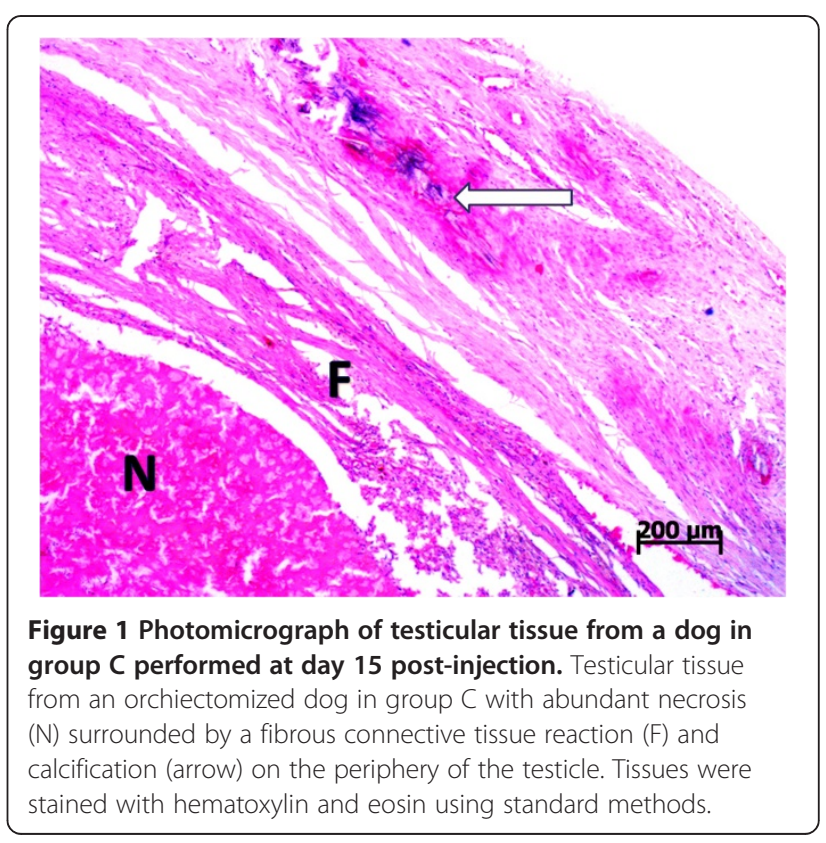




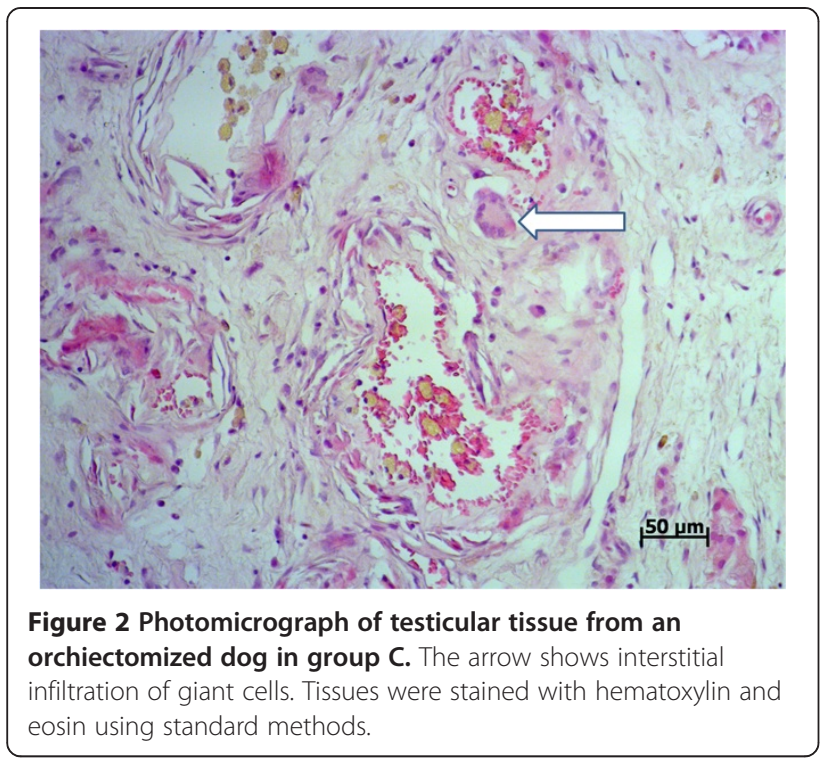

Semen volume, total sperm count and progressive sperm motility

Evaluation of the semen volume collected at $T_{0}$ and $T_{12}$ revealed a significant interaction among groups (Group $\times$ Time interaction: $F=9.84, P<0.001)$. Semen volume declined significantly over time for experimental groups A-D $(P<0.001)$ but not for the control group $\mathrm{E}(P=0.322)$. There was no significant difference between groups at $T_{0}$, but semen volume for all treatment groups was lower than group $\mathrm{E}$ at $\mathrm{T}_{12}(\mathrm{~F}=22.7, P<0.001)$. Changes in semen volume for each group also varied in a dose dependent manner, with the maximum decrease in group $\mathrm{D}$ of $37.6 \%$ (group $\mathrm{A}_{0}: 3.5 \pm 0.44, \mathrm{~T}_{12}: 3.2 \pm 0.59$; group $\mathrm{B} \mathrm{T}_{0}: 2.6 \pm$ $0.36, \mathrm{~T}_{12}: 2.0 \pm 0.44$; group $\mathrm{C}_{0}: 3.4 \pm 0.48, \mathrm{~T}_{12}: 2.4 \pm 0.49$;

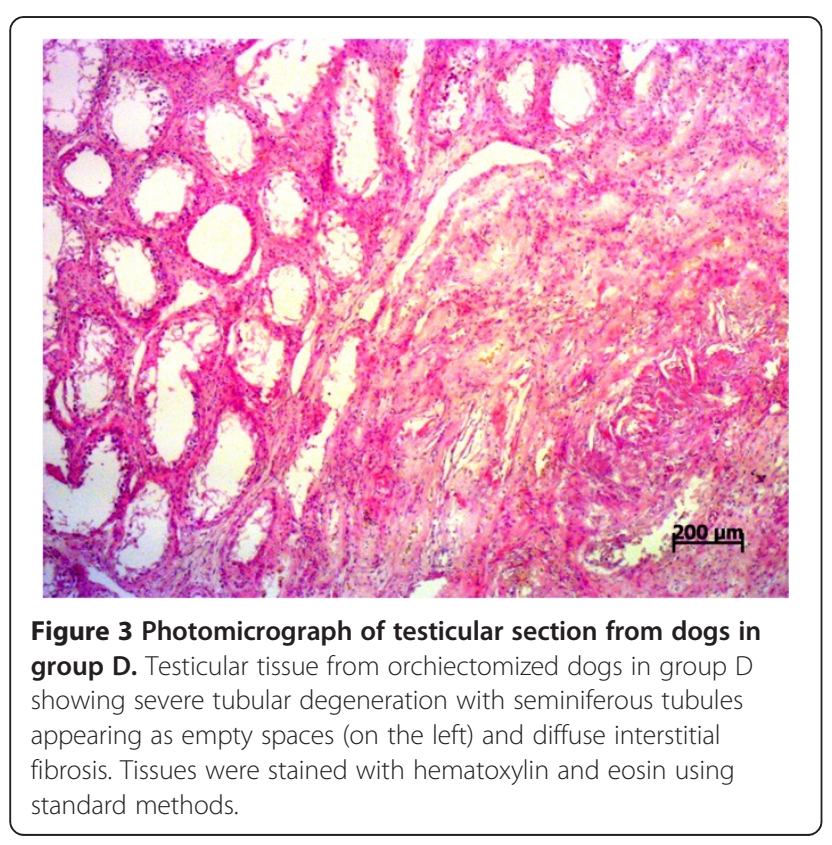

group $\mathrm{D} \mathrm{T}_{0}: 3.1 \pm 0.65, \mathrm{~T}_{12}: 1.9 \pm 0.36$; group $\mathrm{E}_{0}: 3.1 \pm$ $\left.0.56, \mathrm{~T}_{12}: 3.3 \pm 0.56\right)$.

Statistical analyses revealed that the total sperm count differed significantly across time points and between groups (Group $\times$ Time interaction: $F=76, P<0.001$ ) due to significant declines in the experimental groups (but not control group) after treatment with $\mathrm{CaCl}_{2}$. No significant difference between groups was found at $\mathrm{T}_{0}$ : the mean total sperm count $\left(\times 10^{6}\right)$ was $332.9 \pm 51.2$ in group A, $342.4 \pm 35.0$ in group $B, 336.3 \pm 30.1$ in group C, $328.0 \pm 32.5$ in group $D$, and $335.9 \pm 34.9$ in the control group $\mathrm{E}$. The total sperm count in the control group $\mathrm{E}$ also remained stable at $\mathrm{T}_{2}, \mathrm{~T}_{6}$ and $\mathrm{T}_{12}(340 \pm 23.3,313.5 \pm$ $40.6,311.4 \pm 21.4$, respectively). However, after treatment with $\mathrm{CaCl}_{2}$, all experimental groups had significantly lower total sperm counts than the control group $\mathrm{E}$ $(\mathrm{F}=5879, P<0.001)$ and compared to their $\mathrm{T}_{0}$ value $(P<0.001)$ (Table 1$)$.

Total sperm count and progressive motility were inversely associated with the dosage of $\mathrm{CaCl}_{2}$ administered. All experimental dogs were azoospermic at $\mathrm{T}_{2}$ and $\mathrm{T}_{6}$. At $\mathrm{T}_{12}, 6(60 \%)$ dogs in group A remained azoospermic, and 4 dogs $(40 \%)$ were severely oligospermic $(74.5 \pm 6.6$, range 65-80) (Table 1). The mean total sperm count $\left(\times 10^{6}\right)$ in group $\mathrm{A}$ was $29.8 \pm 38.7$ at $\mathrm{T}_{12}$. In group $\mathrm{B}, 8(80 \%)$ of dogs remained azoospermic, and $2(20 \%)$ of dogs were severely oligospermic $(37.5 \pm 10.6$, range $30-45)$ at $\mathrm{T}_{12}$ (Table 1). All dogs in group $\mathrm{C}$ and group $\mathrm{D}$ remained completely azoospermic at $\mathrm{T}_{12}$.

As expected, progressive sperm motility reflected the results of total sperm counts. At $\mathrm{T}_{0}$, motility was $90 \pm$ $4.7 \%$ in group $\mathrm{A}, 75 \pm 7.1 \%$ in group $\mathrm{B}, 80 \pm 8.5 \%$ in group $C, 70 \pm 0.0 \%$ in group $D$, and $80 \pm 5.8 \%$ in the control group E. Motility of sperm in the control group $\mathrm{E}$ averaged $80 \pm 5.8 \%$ at all times tested. It was only possible to measure sperm motility in the treatment groups at $\mathrm{T}_{12}$ for dogs in groups $\mathrm{A}(10 \%$ motility in all 4 dogs) and $\mathrm{B}(5 \%$ motility in both dogs). Statistical analysis of sperm motility was not possible due to the lack of variability among the groups.

Semen collection was easily performed at all time points and no differences were noticed in relation to the $\mathrm{CaCl}_{2}$ treatment groups. Semen collection was not performed in dogs that underwent surgical castration.

\section{Assay of serum testosterone}

The mean hCG-stimulated testosterone levels at $\mathrm{T}_{0}$ were within physiological range (100-1,000 $\mathrm{ng} / \mathrm{dl})$ [24] for all dogs: $591.0 \pm 140.1$ in group A, $581.8 \pm 223.2$ in group $B$, $654.8 \pm 233.1$ in group C, $413.0 \pm 138.1$ in group $D$, and $721.2 \pm 176.2$ in the control group (E). A single intratesticular injection of $\mathrm{CaCl}_{2}$ decreased serum testosterone concentrations in a dose-dependent manner (Table 2). A significant interaction between Group and Time was found 
Table 1 Effects on reproductive parameters 1 year after intratesticular injection of calcium chloride or saline

\begin{tabular}{lllll}
\hline Intratesticular injection & Total sperm count $\left(\times \mathbf{1 0}^{\mathbf{6}}\right)$ & Sperm motility $\mathbf{( \% )}$ & $\begin{array}{l}\text { Serum testosterone concentration } \\
\text { (ng/dL) after hCG stimulation }\end{array}$ & Testicular width (mm) \\
\hline Saline Control (E) & $311.4 \pm 21.4$ & $80 \pm 5.8 \%$ & $735.2 \pm 186.4$ & $24.9 \pm 2.1$ \\
$10 \% \mathrm{CaCl}_{2}$ (A) & $29.8 \pm 38.7^{+}$ & $10 \pm 5.2 \%^{+}$ & $487.7 \pm 144.2$ & $12.9 \pm 1.4$ \\
$20 \% \mathrm{CaCl}_{2}$ (B) & $7.5 \pm 16.2^{++}$ & $5 \pm 2.1 \%^{++}$ & $461.0 \pm 286.6$ & $12.3 \pm 0.9$ \\
$30 \% \mathrm{CaCl}_{2}$ (C) & 0 & - & $299.3 \pm 170.7$ & $12.4 \pm 1.5$ \\
$60 \% \mathrm{CaCl}_{2}$ (D) & 0 & - & $125.7 \pm 48.9$ & $12.0 \pm 0.7$ \\
\hline
\end{tabular}

Effects on reproductive parameters in male dogs were measured 1 year after a single, bilateral intratesticular injection of calcium chloride. Some of the male dogs in groups $C$ and $D$ also underwent surgical castration. Data for dogs in groups $A, B$, and $E$ and dogs in group $C$ and $D$ that did not undergo surgical castration are expressed as mean \pm SD. $+60 \%$ of the dogs were azoospermic, and $40 \%$ were oligospermic. $++80 \%$ of the dogs were azoospermic, and $20 \%$ showed severe oligospermia.

- Undetectable.

(F $=7.40, P<0.001)$. The control group's testosterone level did not change significantly over time, but each experimentally treated group had significantly decreased testosterone levels $(P<0.006)$ (Tables 1 and 2). Compared to pre-injection concentration $\left(\mathrm{T}_{0}\right)$, testosterone levels decreased on average $35.4 \%$ in Group A, $41.7 \%$ in Group B, $70.1 \%$ in Group C, and $60.1 \%$ in Group D. Treatment with $30 \%$ or $60 \% \mathrm{CaCl}_{2}$ showed higher efficacy in decreasing testosterone levels than did treatment with $10 \%$ or $20 \%$ $\mathrm{CaCl}_{2}$. The testosterone levels of dogs treated with $60 \% \mathrm{CaCl}_{2}$ remained near the lower limit of the physiological range throughout the study, whereas testosterone in groups treated with lower concentrations of $\mathrm{CaCl}_{2}$ had increased at $\mathrm{T}_{12}$.

\section{Measurement of testicular width}

At $\mathrm{T}_{12}$, the scrotal widths had decreased significantly by approximately $50 \%$ in all of the $\mathrm{CaCl}_{2}$-treated groups compared with the control group $\mathrm{E}$. The mean values of testicular width $(\mathrm{mm})$ at $\mathrm{T}_{0}$ vs $\mathrm{T}_{12}$ were $24.6 \pm 2.5$ vs $12.9 \pm 1.4$ in group A; $23.8 \pm 1.1$ vs $12.3 \pm 0.9$ in group $\mathrm{B}$; $24.3 \pm 1.2$ vs $12.4 \pm 1.5$ in group $C$; $24.3 \pm 1.2$ vs $12.0 \pm$ 0.7 in group D; and $24.9 \pm 2.1$ vs $24.9 \pm 2.1$ in the control group (E) (Table 1). As with sperm count and testosterone, analysis of testicular width showed an interaction between Group and Time $(\mathrm{F}=243, P<0.001)$. Testicular width in experimental groups differed from the $\mathrm{E}$ group $(P<0.001)$ due to reduced testicular width measurements at $\mathrm{T}_{12}$ for the experimental groups $(\mathrm{F}=525.7, P<$
0.001). As expected, the testicular widths in the control group E remained unchanged over time.

\section{Discussion}

The results of this long-term study have important implications for nonsurgical sterilization of male dogs. Treatment with $\mathrm{CaCl}_{2}$ resulted in atrophy of the testicles and significantly lower semen volume, total sperm count, testosterone levels and testicular measurements compared with the control group. Although a complete fertility evaluation of characteristics such as sperm morphology was not performed, the complete absence of sperm seen at higher doses indicates likely contraceptive effect.

A dose-dependent effect on the reproductive characteristics was found with increasing concentrations of $\mathrm{CaCl}_{2}$ resulting in more durable azoospermia, but simultaneously leading to higher risk of complications.

Measuring testicular size and injecting a predetermined concentration of $\mathrm{CaCl}_{2}$ is expected to be more practical than weighing individual dogs and preparing customized injection solutions as reported in previous studies [2,12-14]. Our results indicate that our approach is useful and effective and could be applied to a field neutering campaign or management of a population of stray dogs.

The minor discomfort during injection of $\mathrm{CaCl}_{2}$ or saline noticed in a few dogs was caused by the needle and intra-testicular pressure. Afferent nerve endings associated with pain sensation are located only on the scrotal skin and in the capsule of the testis rather than within

Table 2 Mean (+/- SD) testosterone levels (ng/dL) in serum following hCG stimulation

\begin{tabular}{llllll}
\hline Group & $\mathbf{T}_{\mathbf{0}}$ & $\mathbf{T}_{\mathbf{2}}$ & $\mathbf{T}_{\mathbf{6}}$ & $\mathbf{T}_{\mathbf{1 2}}$ & Ave $\mathbf{T}_{\mathbf{2}}-\mathbf{T}_{\mathbf{1 2}}$ \\
\hline $10 \% \mathrm{CaCl}_{2}$ (A) & $591.0 \pm 140.1$ & $468.8 \pm 105.4$ & $189.5 \pm 79.0$ & $487.7 \pm 144.2$ & $382.0 \pm 167.0^{\mathrm{a}, \mathrm{b}}$ \\
$20 \% \mathrm{CaCl}_{2}$ (B) & $581.8 \pm 223.2$ & $257.0 \pm 179.3$ & $300.0 \pm 211.3$ & $461.0 \pm 286.6$ & $339 \pm 107.5^{\mathrm{a}, \mathrm{b}}$ \\
$30 \% \mathrm{CaCl}_{2}$ (C) & $654.8 \pm 233.1$ & $128.6 \pm 50.5$ & $159.9 \pm 66.8$ & $299.3 \pm 170.7$ & $195 \pm 90.8^{\mathrm{a}, \mathrm{b}}$ \\
$60 \% \mathrm{CaCl}_{2}$ (D) & $413.1 \pm 138.1$ & $209.8 \pm 25.7$ & $103.5 \pm 13.5$ & $125.7 \pm 48.9$ & $146 \pm 56.0^{\mathrm{a}, \mathrm{b}}$ \\
Saline Control (E) & $721.2 \pm 176.2$ & $663.6 \pm 154.3$ & $640.4 \pm 149.9$ & $735.2 \pm 186.4$ & $679.7 \pm 49.4$ \\
\hline
\end{tabular}

$T_{0}, T_{2}, T_{6}$, and $T_{12}$ indicate the time-points (time zero, 2 months, 6 months, and 12 months, respectively) following intratesticular injection. Data are expressed as mean $\pm S D$. After injection of calcium chloride, levels of testosterone in serum decreased: $a=$ significant within group difference comparing $T_{0}$ to $T_{2}-T_{12} ; b=$ significant between group difference comparing group $A-D$ to control group $E$ at $T_{2}-T_{12}$. 
the testicular parenchyma. Therefore, these nerve endings may have been stimulated as intra-testicular pressure increased during and immediately following injection [24]. The injections were well tolerated, an important welfare consideration.

We found that intratesticular injection of $\mathrm{CaCl}_{2}$ in a saline solution as a nonsurgical sterilizing agent had a dose-dependent effect on dogs. Intratesticular injection of $\mathrm{CaCl}_{2}$ achieved and maintained infertility for at least 6 months. However, $60 \%$ of the dogs receiving $10 \% \mathrm{CaCl}_{2}$ and $20 \%$ of the dogs receiving $20 \% \mathrm{CaCl}_{2}$ had regained some testicular activity by 12 months PI. Although the maximum response in terms of contraception was seen with injections of $30 \% \mathrm{CaCl}_{2}$ and $60 \% \mathrm{CaCl}_{2}$, these high doses resulted in a higher risk of complications that might necessitate emergency surgery (which was performed in $20 \%$ and $60 \%$ of the dogs receiving these doses, respectively). Use of such high concentrations is contraindicated, as complications cannot be managed in stray dogs or during high-volume neutering campaigns.

In agreement with the findings of previous studies, a $20 \%$ solution of $\mathrm{CaCl}_{2}$ was the most effective dose that resulted in elimination of sperm in most dogs but did not result in serious complications $[2,13,15]$. Previous short-term investigations reported complete sterilization with various dosages and formulations of $\mathrm{CaCl}_{2}$ [2,12-15]. Importantly, our study showed a certain level of sperm production one year after treatment with the lower concentrations $(10 \%$ and $20 \%$ ). Although the partial recovery of sperm production may not be sufficient for restoration of fertility in male dogs, we cannot exclude the possibility that recovery of fertility could occur. Levels of serum testosterone also began to increase at $\mathrm{T}_{12}$ in groups A-C. These results point to the importance of long-term studies to gauge the effectiveness of chemical castration methods, which is critical to their use in stray dog population management programs.

\section{Conclusions}

Our study confirmed the effectiveness of an intratesticular $\mathrm{CaCl}_{2}$ injection as a promising sterilization agent. A practical dosing system by testicular width was demonstrated and a $20 \%$ solution of $\mathrm{CaCl}_{2}$ was identified as the most effective dose without risk of serious complications. However, in contrast to previous reports that assumed permanent sterilization based on testicular histology, in conducting the first long-term study we found that some testicular function had returned after one year at all but the highest dose. Given the considerable promise of this method, further studies should explore use of different solvents (alcohol, lidocaine) with the goal of boosting $\mathrm{CaCl}_{2}$ efficacy at the well-tolerated $20 \%$ dose.

\section{Competing interests}

The authors declare that they have no competing interests.

\section{Authors' contributions}

$R L$ and $E L$ were involved in the concept and design of the study. RL was involved in the analysis and interpretation of results, semen sampling and evaluation, and preparation of this manuscript. $R L, G A$, and $E L$ were involved in the revision of study design. $R L$ and $G A$ performed the intratesticular injection of the dogs. RL, GA and FS performed the ultrasonography. FS performed the acquisition of data and was responsible for the clinical care of the dogs and blood sampling. FM performed the histological examination and photomicroscopy. $\mathrm{RL}, \mathrm{GML}$ and $\mathrm{EL}$ were involved in revision of the manuscript. All authors have read and approved the manuscript.

\section{Acknowledgements}

The authors credit Dr. LM Koger (deceased) and his team for first publishing pilot studies on this technique. The authors appreciate Dr. Kuladip Jana and Dr. PK Samanta for their persistent and pioneering work in this field over several decades. The authors are deeply grateful to Parsemus Foundation, Berkeley, California, USA for vision, financial assistance, and continuous support. Also, the authors sincerely acknowledge Dr. Linda Brent for language revision, statistical analysis, interpretation of data, and logistical support.

\section{Author details}

${ }^{1}$ Department of Emergency and Organ Transplantation (DETO), Section of Veterinary Clinic and Animal Production, University of Bari Aldo Moro, SP per Casamassima km 3, 70010 Valenzano BA, Italy. ${ }^{2}$ Parsemus Foundation, PO Box 2246, 94702 Berkeley CA, USA. ${ }^{3}$ Department of Veterinary Science, University of Messina, Polo Universitario dell'Annunziata, Viale Annunziata, 98168, Messina, Italy.

Received: 6 June 2013 Accepted: 5 September 2014

Published online: 14 October 2014

\section{References}

1. Ortega-Pacheco A, Bolio-Gonzalez ME, Colin-Flores RF, Sauri-Arceo CH, Gutierrez-Blanco E, Jimenez-Coello M: Linde Forsberg C: evaluation of a Burdizzo castrator for neutering of dogs. Reprod Dom Anim 2006, 41:227-232.

2. Jana K, Samanta PK: Sterilization of male stray dogs with a single intratesticular injection of calcium chloride: a dose dependent study. Contraception 2007, 75:390-400.

3. Pineda MH: Contraceptive Procedures for the Male Dog. In Current Therapy in Theriogenology. 2nd edition. Edited by Morrow DA. Philadelphia: WB Saunders Co; 1986:563-566.

4. Kutzler M, Wood A: Non-surgical methods of contraception and sterilization. Theriogenology 2006, 66:514-525.

5. Freund J, Lipton MM, Thompson GE: Aspermatogenesis in the guinea pig induced by the testicular tissue and adjuvants. J Exp Med 1953, 97:711-726.

6. Wiebe JP, Barr KJ: The control of male fertility by 1,2,3-trihydroxypropan (THP; glycerol): rapid arrest of spermatogenesis without altering libido, accessory organs, gonadal steroidogenesis and serum testosterone, LH and FSH. Contraception 1984, 29:291-302.

7. Oliveira EC, Moura MR, de Sá MJ, Silva VA Jr, Kastelic JP, Douglas RH, Marques AP Jr: Permanent contraception of dogs induced with intratesticular injection of a zinc gluconate-based solution. Theriogenology 2012, 77:1056-1063.

8. Aiudi G, De Sandro Salvati A, Binetti F, Matarrese R, Leoci R, Lacalandra GM Chemical sterilization in dogs with intra-epididymal injection of $5 \%$ chlorhexidine solution. Reprod Dom Anim 2007, 42:83.

9. Immegart HM, Threlfall WR: Evaluation of intratesticular injection of glycerol for nonsurgical sterilization of dogs. Am J Vet Res 2000, 61:544-549.

10. Fahim MS, Wang M, Sutcu MF, Fahim Z, Youngquist RS: Sterilization of dogs with intra-epididymal injection of zinc arginine. Contraception 1993, 47:107-122.

11. Calcium Chloride. [http://www.drugs.com/pro/calcium-chloride.html]

12. Koger LM: Calcium chloride, practical necrotizing agent. Bovine Pract 1977, 12:118-119.

13. Koger LM: Calcium chloride castration. Mod Vet Pract 1978, 59:119-121.

14. Samanta PK: Chemosterilization of stray dogs. Indian J Anim Hith 1998, $37: 61-62$. 
15. Jana K, Samanta PK: Clinical evaluation of non-surgical sterilization of male cats with single intra-testicular injection of calcium chloride. BMC Vet Res 2011, 7:39.

16. Naz RK, Talwar GP: Immunological sterilization of male dogs by BCG. Int J Androl 1981, 4:111-128.

17. Kutzler MA: Semen collection in the dog. Theriogenology 2005, 64:747-754.

18. Leoci R, Aiudi G, De Sandro Salvati A, Silvestre F, Binetti F, Lacalandra GM: Ultrasound as a mechanical method for male dog contraception. Reprod Dom Anim 2009, 44:326-328.

19. Freshman JL: Semen collection and evaluation. Clin Technol Small Anim Pract 2002, 17:7.

20. Santana M, Batista M, Alamo D, Cabrera F, González F, Gracia A: Influence of sexual stimulation and the administration of human chorionic gonadotrophin on plasma testosterone levels in dogs. Reprod Dom Anim 2012, 47:43-46.

21. Post K: Effects of human chorionic gonadotrophin and castration on plasma gonadal steroid hormones of the dog. Can Vet J 1982, 23:98-101.

22. Kawakami E, Hori T, Tsutsui T: Changes in plasma LH and testosterone levels and semen quality after a single injection of hCG in two dogs with spermatogenic dysfunction. J Vet Med Sci 1998, 60:765-767.

23. Woodall PF, Johnstone IP: Scrotal width as an index of testicular size in dogs and its relationship to body size. J Small Anim Pract 2008, 29:543-547.

24. Christensen GC: The Urogenital Apparatus. In Miller's Anatomy of the Dog. Edited by Evans HE, Christensen GC. Philadelphia: WB Saunders Co; 1979:544-601.

doi:10.1186/s13028-014-0063-1

Cite this article as: Leoci et al:: A dose-finding, long-term study on the use of calcium chloride in saline solution as a method of nonsurgical sterilization in dogs: evaluation of the most effective concentration with the lowest risk. Acta Veterinaria Scandinavica 2014 56:63.

\section{Submit your next manuscript to BioMed Central and take full advantage of:}

- Convenient online submission

- Thorough peer review

- No space constraints or color figure charges

- Immediate publication on acceptance

- Inclusion in PubMed, CAS, Scopus and Google Scholar

- Research which is freely available for redistribution 